\title{
MUKAYESELİ HUKUKTA TAŞINIRIN MALİK OLMAYANDAN İKTISABI
}

\section{Doc. Dr. Akn DÜREN}

Küçük bir Hollanda şehrinde yaşayan (A) ailesi, on yuldanberi besledikleri ve çok sevdikleri köpeklerini, tatil için yabancı bir ülkeye hareket etmeden önce, (B) ye ait bir hayvan pansiyonuna bırakmıştır. Tatil dönüşü köpeği almak için hayvan pansiyonuna (A) ailesinin bir ferdi geldiğinde, pansiyon sahibi (B), köpeğin öldüğüüü söylüyor. Kendileri için acı bir süpriz olan bu olaydan birkaç gün sonra (A) ailesi, köpeklerini Amsterdam'da (C) ismindeki bir aile ile beraber gezerken görüyor. (C) ailesinin reisi köpeği birkaç hafta önce, köpeğin kaldığı pansiyonun sahibinden iyi inançla satın almıştır. Köpek kime aittir? (A) ailesine mi? yoksa (C) ailesine mi? Hollanda Hukukunda ve diğer modern hukuk sistemlerinin çoğunda iyi inançlı müktesip (C) malik olur. Hukuk öğrenimine yeni başlamı̧ öğtencilerden oluşan bir sınıfta anket yapan bir Profesör henüz hukuki bilgileri yeterli olmayan bu ögrencilerin çoğunun hukukî hissinin, böyle bir olayda, köpeğin belki (C) tarafundan ödenecek bir tazminat karşılı̆̆mda (A) ailesine iadesi olduğunu saptayacaktır. Taşınırı, malik olmayandan iktisap etmiş üçüncü şahıstan, malikin talep edebilip edemeyeceği sorunu her devirde söz konusu olmuştur. Bu sorunla ilgili kurallar M.Ö. 2000 yllmmn ilk asırlarmdaki Hamurabi Kanunu'nda ve Hun Kanunlarinda bulunduğu gibi, bütün modern kanunlar ve kanun tasarıları bu soruna hasredilmiş kuralları ihtiva ederler Aşağıdaki incelemelerimizde, mülkiyet sorununun çözülmesi gereken iki olaydan hareket edeceğiz. Ilk olay: malik (A) maddî bir taşınırı (B) ye (vedia alana, kiracrya, ariyet alana) fer'î zilyed olarak veriyor. Bu, emniyeti kötüye kullanıyor, taşmırı iyi inançlı (C) ye satıyor ve teslim ediyor. (A) ve (C) arasındaki hukukî ihtilâfta mülkiyet acaba (A) ya mı? yoksa (C) ye mi? tanınmalıdır sorunu, hukukçular için çözümlenmesi zor bir sorundur. Çünkü her iki şahıs da hukuki himayeye lâyıktır. Ancak her ikisinin aynı anda bu huhukî himayeden yararlanabilmeleri tabiatıyla mümkün değildir. Hu- 
kuk Tarihi ve Mukayeseli Hukuk, birçok çöümlerin düşünüldüğünü ve getirildiğini bize göstermektedir. Çözüm yollarından aşağıdakileri zikrediyoruz:

- (A) her zaman malik kalır.

- (C) doğrudan doğruya malik olur (her zaman veya bazı şartlar altında; örneğin iyi inanç, muteber bir hukukî sebep, ivazlı iktisap).

- (C) ancak - çoğu kez zikredilen şartlar altında- (A) taşınırı arzusuyla (B) ye vermişse, doğrudan doğruya malik olur. (A) taşınırı arzusu hilâfına elinden çıkarmışsa; üçüncü şahıs ancak belli bir sürenin geçmesinden sonra malik olur.

- (C), bazı şartlar (iyi inanç, muteber bir iktisap sebebi) yerine gelmişse -belli bir süre sonra- kazandırıcı zamanaşımılla malik olur.

- (C) asla malik olamaz, fakat belli bir süre sonra (A) nı istihkak davasına karşı ileri sürebileceği bir def'îye sahip olur. (A) nin dava hakkı zamanaşımıyla ortadan kalkar.

- Ortalama çözüm yolları olarak aşă̆ıdaki düzenlemeler kabul edilmiştir: (C) malik olmayandan iktisap etmis olmasına rağmen malik olur. Ancak (A) ya, belli bir süre içinde kendi maImı geri satın alma hakkı tanmır. Veya: (A) malik kalır ve taşmırı (C) den geri isteyebilir. Ancak (C) ödemiş olduğu bedeli veya eşyanın kıymetini veya kıymetinin yarısı, (A) kendisine ödeyinceye kadar, eşyayı teslimden imtina edebilir. Bu son çözüm yollarına özellikle (C) nin taşını pazardan veya açı arttırmadan satın aldığs hallerde rastlanır.

Modern hukuk sistemlerinin mukayeseli tetkikine girişmeden önce, Hukuk Tarihine ilişkin bazı görüşleri zikredeceğim.

Roma ve Cermen Hukuk sistemlerinin taşınır mülkiyet kuralları arasında bir kıyas yapmak âdettir. Roma Hukukunda malik taşınırı herkesten rei vindicatio davasi ile her zaman geri alabilir. Cermen $\mathrm{Hu}-$ kukunda ise malikin kendi arzusuyla eşayı teslim ettiği bir kimseden iktisapta bulunmuş üçüncü şahıs, her zaman muamelâttaki güven nedeniyle himaye edilirdi. Roma Hukukunda malik esyasın, malik olmayandan (a non dominus) iktisap eden ve nemo plus iuris in alium transferre potest quam ipse habet kuralı gereğince malik olamayan her üçüncü şahıstan talep edebilirdi. Bu sistem Ortağ Çă̆ Romanistlerince meşhur bir kuralla ifade edilmişti: ubi rem meam invenio, $i b i$ vindico ( malımı nerede bulursam, orada alırım). Romalı'lara göre 
mülkiyet genellikle, arzu hilâfma kaybedilemiyen bir haktı. Ancak Cermen'lerin de iyi inançlı müktesibi himaye etmeyi ve böylelikle muamelâttaki güveni sağlamayı göz önünde tuttukları tamamiyle muhaldir. Q̧eşitli Barbar Kanunlarmdan biliyoruz ki, ancak üçüncỉ şahısta bulunan çalınmış ve kaybedilmiş eşyalar talep edilebilirdi ve fer'î zilyedlik tesis edilecek şekilde verilmiş eşyalar res praestita'ya ilişkin kurallara müsteniden âkid tarafmdan geri istenilirdi. Kaynaklardan daha fazla bir bilgi edinilememektedir. Mobilia non habent sequelam gibi hukukî deyimler, Roma sisteminden farklı olarak ticarî muamelât yararma iyi inançl1 müktesibin himaye edildiği Orta Çağ'da ortaya çımıştır.

Fransa'da üçüncü şahıs için aynı yararlı sonuca ancak $18 \mathrm{ci}$ yüzyılın başlarnndan itibaren Paris Chatelet'i tarafindan, «en fait de meubles la possession vaut titre» ( taşınırlarda zilyedlik mülkiyete karinedir) kuralının tatbiki ulaştırmıştır. Bourjon 1747 yllında yayınladığ 1 Droit Commön de la France adlı eserinde, bu kuralın taşınırlardaki kazandırıcı zamanaşımı yerine konduğunu ve ticari menfaatin bunun doğmasma sebep olduğunu (l'interet du commerce l'exige oinsi) yazmaktadır. Paris Chateleti'nin dava dosyaları çok kısa tutulduğu için - $\mathrm{Pa}$ ris'te arşivlerde yaptığım araştırmalarda tespit ettiğim gibi-- kuralın menşei hakkında bunlarla daha fazla bilgi edinmek ümidi kalmamaktadrr. Her ne olursa olsun bana, modern kanunlardaki kurallarm (Bourjon'dan alman 'en fait de meubles la possession vaut titre' kuralına dayanan Fransız Medenî Kanununun 2279 ve Alman Medenî kanununun 932 ci maddesi gibi) Cermen Hukukuyla hiçbir ilişkileri olmadığı görünüyor.

Romanistler, üçünci̇ şahıslarmm durumunun Roma Hukukunda kötü olduğu tenkidine karşıllı, üçüncü şahsın kısa bir sürel sonra malik olabileceği kısa zamanaşımı sürelerinin (Klâsik Hukukta 1 Iustinianus Hukukunda 3 yil) tespit edildiğini genellikle itiraz olarak ileri sürerler. $\mathrm{Bu}$ itiraz yanlıştır. Zira taşımrların ustcapio ile iktisabl oldukça nadir görülen bir haldi (Gaius'un 2,50 de çok iyi ifade ettiği gibi: In rebus mobilibus non facile procedit, ut bonae fidei possessori usucapio competat.). Bilindiği gibi res furtivae'ler kazandırıcı zamanaşımı ile iktisap edilemezdi. Res furtivae'lere emniyetin kötüye kullanılmasina konu olan eşyalar da dahildir. Ancak birkaç istisnaî halde taşınır eşyaların üucapio'su mümkündür. Hareket noktası olarak zikrettiğimiz hallerin her ikisinde de üçüncü şahıs ne teslimle, ne de zamanaşımı ile malik olur.

Yukarıdaki açıklamalardan anlaşıllyor ki, modern hukuklarda sorunumuzun düzenlenmesine takaddüm eden tarihî bilgilerin bir çok 
açıdan yeniden gözden geçirilmesi gerekiyor. Roma ve Cermen sistemlerinin alşa gelinmiş kıyaslaması ve Romanistler tarafindan yapılan itiraz, düzeltmeye veya ince farklar yaratmaya ihtiyaç göstermektedir.

Şimdi modern hukuk sistemlerine yönelecek olursak, bu sistemleri esas itibariyle üç ana gruba ayırabiliriz. Ilk grubun hukuk sistemleri (I), bilerek veya bilmeyerek Roma Hukukunu taklit ederek, zikrettiğimiz her iki halde önceki malik (A) ya, eşyayı üçüncü şahıs müktesipten istihkak davasıyla alma hakkın verirler. Ikinci grup hukuk sistemleri (II), zikrettiğimiz her iki halde üçüncü şahıs müktesibe mülkiyeti iktisap ettirirler. Ortalama bir çözüm, ilk zikredilen halde mülkiyeti iyi inançh üçüncủ şahıs müktesibe tanıyan; ikinci halde, malını arzusu hilâfına elden çıarmış malike istihkak davası veren üçüncü grup (III) hukuk sistemleri tarafindan tercih edilmiştir Esasen yakından bir inceleme bu üç grubun hukukî düzenlemeleri arasında, ilk bakışta göründüğü gibi, o kadar kesin farklar olmadığın gösterir. Zira bu düzenleme ler tanınan birçok istisnalarla birbirlerine oldukça yaklaşmışlardır.

I - Ilk grupta Ispanyol, Portekiz, Güney Afrika ve Ingiliz hukukları buluyoruz. Ispanyol Hukukunda Yüksek Mahkeme, 'taşıırlarda zilyedlik hukukî sebep sayılır' kuruluşunu, İustinianus Hukukundaki gibi ,üç yıl devam eden zamanaşımının hukukî sebebi anlamma gelecek şekilde yorumlamıştır. Eşyanın zilyedliğini arzusu hilâfına kaybetmiş ve bu nedenle onu her üçüncü şahıstan zamanaşımı tamamlanıncaya kadar iadesini talep edebilecekler arasinda Jurisprüdans, emniyetin kötüye kullanılmasına konu teşkil eden eşyaların malikini de sayar.

Diğer hukukların çoğunda bu deyimler, istihkak hakkı sadece çalınan veya kaybedilen eşyanın malikine tannacak şekilde, farklı olarak yorumlanmıştır. Uç̧üncü şahıs eşyayı açık arttırmadan satın almışsa, ödemiş olduğu satı̧̧ bedelinin iadesini istihkak davacısı malikten talep edebilir. Eşya umuma açık bir mağazadan üçüncü şahıs tarafindan iyi inançla satın alındığı takdirde, bu, doğrudan doğruya malik olur. Portekiz Hukuku hemen hemen Ispanya Hukuku ile aynıdır. Bu hukukta sadece, zamanaşımı için daima muteber bir hukukî sebep gereklidir. Güney Afrika Hukuku taşıırın esas itibariyle istihkak davası ile istenebilmesini Roma - Hollanda Hukukundan iktibas etmiştir. Eski Hollanda Hukukunda aşağıdaki kurallara ilişkin emareler de vardır. Resmî bir açık arttırmaya iş̧irak eden iyi inançlı alıcı malik olur. Aynı şekilde taşınırı bir komisyoncudan veya bir simsardan, aracı şahsın gerçek malik olduğuna kendisini inandıracak bir görünüs yaratmasıyla, satın alan kimse de malik olur. Bu çözüm şekilleri modern Güney Afrika öğretisinde Ingiliz (estoppels) teorisi ile açılanır. İngiliz Hukukunda 
da taşınırlar genellikle her üçüncü şahıstan geri alınabilir. Eફ̧yayı malik olmayandan alan üçüncü şahıs mülkiyeti, Ingilizlerin Common Law'da 'nemo dat, quod non habet şeklinde isimlendirdikleri temel prensip nedeniyle iktisap etmez. Burada Ulpianus'a ait meşhur D.50, 17,54 den iktibas olmadığı, pek inandırıcı görünmüyor. Bu temel prensibin en önemli istisnası, pazardan satın almış iyi inançlı müktesip için yapılmıß tır. Bu özel kural, 1893 tarihli Sale of Goods Act'deki temel prensibin diğer istisnalarlarıla birlikte kabul edilmişti.

Pazardan alıs-veriş yapan alıcı ile, Londra da bir mağazada normal şekilde satılan bir eşyayı alan kimse bir tutulmuştur. Ứçüncü şahıs müktesip, eşyanın hırsızlık (larcing) malı olduğu hakim kararıyla tespit edilmişse, himaye edilmez. Altcı durumunda bulunan üçüncü şahsın himaye edildiği bazı haller şunlardır: Temlik edenin temlike yetkili olmadığını ispat edecek bir hukukî sebebin bulunmaması; resmî bir açı arttırmadan satın alma; komisyoncunun aracılığ ma ve malikin ihmali neticesinde bir kimsenin alıcıda malik olduğu görünüşünü yarattığı haller -oldukça sınırlı-. Ingiliz hukukçuları ,estoppels, nazariyesi ile bu teşvik edilmiş mülkiyet hallerini doğmatik olarak açıklamışlardır. Bütün bu hallerde sadece, bona fidei purchaser for velue without notice, yani iyi inançla satm alan ve satıs bedelini ödemiş alıcı himaye edilmiştir. Böylece ,nemo dat, quod non habet, prensibine ticarî muamelât yararma önemli tahditler getirilmiştir.

II - Yeni ILalyan Medenî Kanunu 1153 cü maddesinde, eski Italyan Hukukunca da bilinen ve Fransız Hukukundan alınmış olan malikin eşyayı arzusu ile veya arzusu hilâfma elinden çıkarması halleri arasındaki ayırımdan vazgeçmiştir. Italyan Hukukuna göre, temlike yetkili olmayan bir kimseden muteber bir hukukî sebebe müsteniden bir taşmırın zilyedliğini iyi inançla elde eden herkes mülkiyet elde eder. Yani İtalyan Hukuku taşınım iyi inançlı müktesibinin himayesinde çok fazla ileri gitmiştir. Italyan Medeni Kanununun 1153 maddesine müsteniden mülkiyet iktisabmm, bir ivaz mukabilinde iktisapta bulunan müktesip için tahdit edilmesi veya bir ivaz vermeksizin iktisapta bulunan müktesibin de bu elverişli hukukî duruma sokulması gerekip gerekmediği literatürde münakaşa edilmektedir. Jurisprüdans henüz kesin bir çözüme varamamıştır.

Isveç'te daha XIX cu yüzyılda Jurisprüdans, eşya malikin arzusu ile mi veya arzusu hilâfina zorla mı elinden çıkmuştır sorununu söz konusu etmeden, mülkiyet hakkmı, malik olmayandan iktisap eden iyi inançlı müktesibe tanımıştır. Ancak Isveç Hukukunda üçüncü şahsm himayesi sınırsız değildir. Zira asıl malik eşyanın değiş-tokuş kıymetini üçüncü şahsa verirse, eşyanın iadesini ondan talep edebilir. 
III - Kara Avrupası hukul sistemlerinin çoğu ortalima hir yol

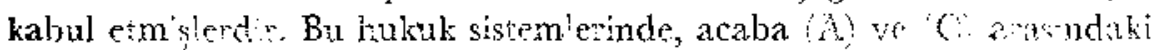

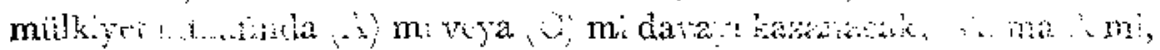

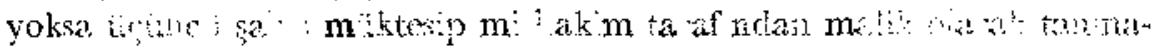

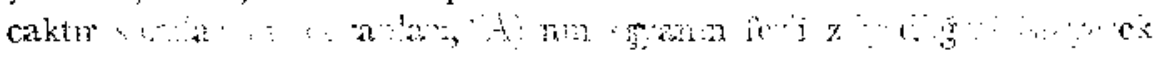

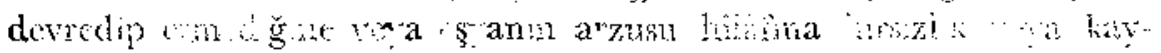

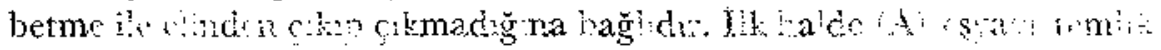

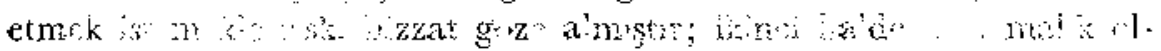
mayalin s. etmemiştir.

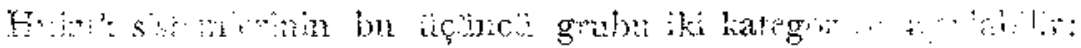

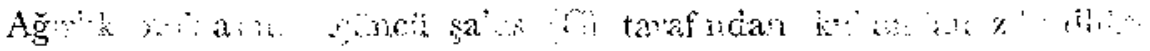

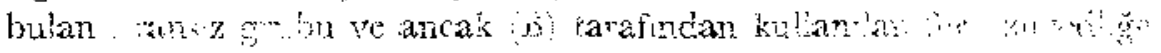

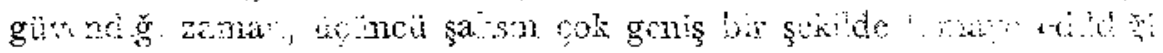
A'mas: gram.

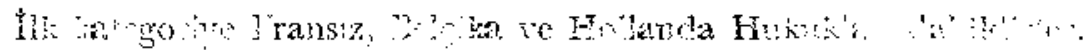

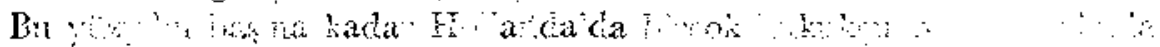
Yük

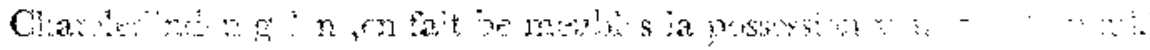

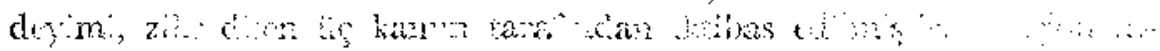

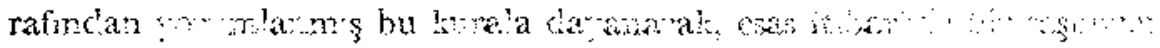
her

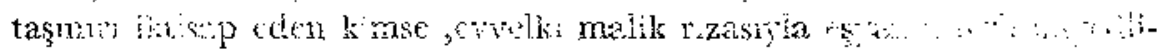

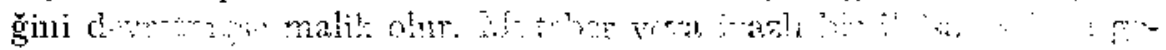

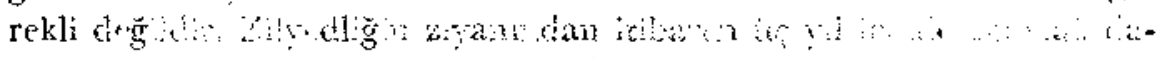

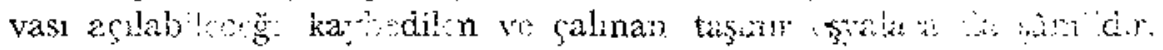

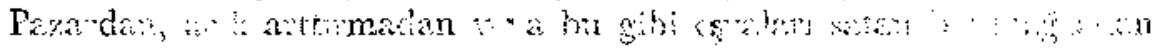

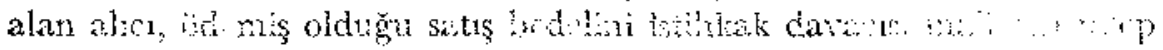

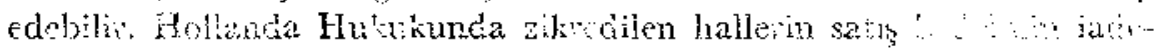

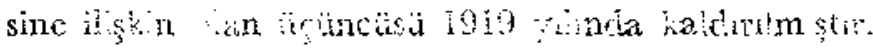

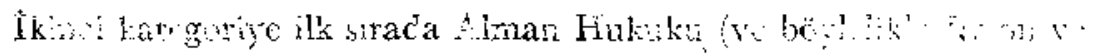

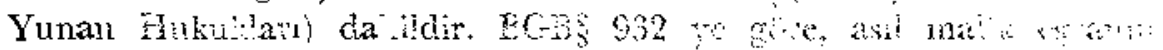

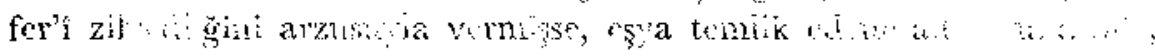

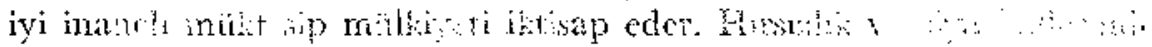

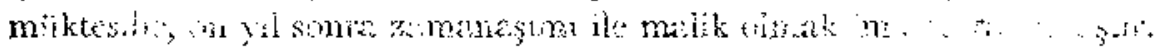

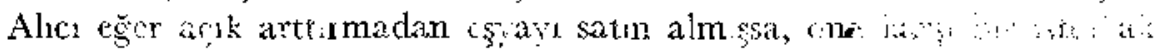

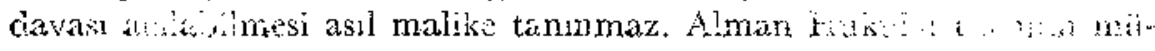

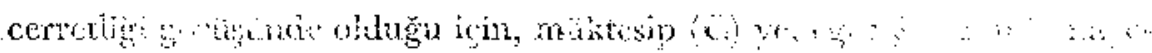

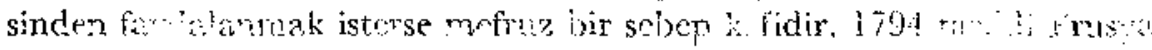

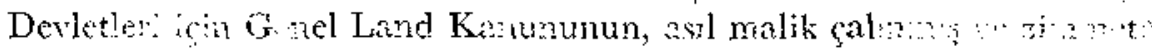

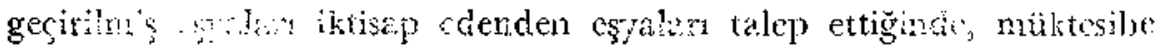


tanıdığı laak modern Alman Hukukunda mevcut değildir. BGB § 932 de 'sebep olma prensibi' ve meşruiyet nazariyesi kaldırılmıştır. Assl malik (A), eşyayı (B) ye emaneten vermekle (C) de bir gưuüıüş yarattığı için, (B) nin fer'î zilyedlĭğine güvenerek iktisapta bulunan (C) malik sayiır. (C), (B) nin malik olduğunu zannetmişse, A!man Hukukunda mülkiyeti iktisap eder.

BGB § 932 ye dayanan üçüneü şahıs, bir ivaz mukabilinde iktisapta butummamı olsa bile, asıI malik ona karş1 $\S 822$ deki zenginlesme davasını açabilir.

Alman işgalinden kurtulduktan beş yll sonra, Hollanda Yüksek Mahkemesi 5 Mayıs 1950 de Alman meşruiyet nazariyesini benimsedi. Yüksck Walkems $\S 2014$ fikra 1 in t $e$ slimle mülkiyetin iktisabı için gerekli şartlardan sadece birimi, temlik yetkisini nazarı itibara a!madı̆gııa lavar verdi. Yeni Hollanda Medenî Kanun tasarısı genellikle, daha iyi ifade edilmiş olsa bile (\$3.4.2.3a) bu konuda yürürlükteki Lukuka katılmaktadır. Yenilik, istihkak davast. olanağını kaybetmiş matike, Isvoç'te tanındı̆̆ gibi, evvelce kenänine ait o.an eşyayı üçüncä şahıstan üç yıl içinde geri satın alma hakkının verilmiş olmasıdır. Taşınılar iç̧ üç yıllık bir zamanaşımı da teklif ediłmektedir.

İsviçre ve Avusturya Hukuklari, Alman Hukukundan daha aşağı bir düzeydedirler. İsviçre düzenlemesi, Isviçre Medenî Kanununun 930 v.d. maddelerinde bulunur. En öncmli fark, illîlik sistemi nedeniyle mịktesibin ancak muteber bir hukukî sebebe müsteniden iktisap etmişse ma!ik olm sıdır. Çatınm vs ve kaybolmuş eşyalara gelince, ïçüncü şałııs müktesibe istilkak davası (monkul davası) beş yıl içinde açıłabilir. Böyle bir esyayı fazardan, açık arttırmadan ve bu gibi eşyayı satan bir kimseden almı̧̧ olan, istilıkak davacısından ödemiş olduğu satış bedelinin 'iadesini isteyobilir. Avusturya Hukuku, kendisine emanet brrakilan bir kimseden (vedia alan ve benzerlcri) iktisapta bulunan, eğer muteber ve ivazh bir iktisap sebebine sahipse korur.

$\mathrm{Bu}$ konferansımm sonunda vardığım neticelere geliyorum. Bana özel hukukun bu kısmmin yenileştirilmesi strasında, her ülke Parlamertolarmm dikkatine sunulmasi gerekli münakaşalı noktaları, kısacası hukukun gelectk on ylda hangi yönde gelişmesi gerektiğini belirtmek uygun gelmektedir.

1. Hemen hemen bütün anlamın kaybettiği için, rızas lle ve rızası olmadan zilyedliğgn kaybı arasindaki ayırımdan vazgeçilecek oluisaz, hukukî sistem düzelir. Aliş-veriş Jłayatı çłarına iyi inançlı üçüncü şahıs mültesibin himavesi gerçektirilmek isteniyorsa, o zaman. Italyan Hukuk sistemi benimsenmelidir. Úçüncü şahıs açısından rıza ile ve rıza olmak- 
sızın zilyedlik kaybı hallerini farklı bir işleme tâbi tutmak hiçbir şey ifade etmez. Durum (A) açısından incelenirse nasıl bir netice verir? Bir otomobili tamire vermek ,bir kürk mantoyu vedia olarak bırakmak, bir kitabı âriyet olarak vermek işlemlerinde rıza ile kavramı çok nisbîdir, zira sosyal ilişkilerde hemen hemen başka türlü hareket edilemez. Bir eşyayı emaneten veren kimse, daha büyük bir riski göze aldığ 1 için her zaman himaye edilmemelidir. Otel kasasma pahalı mücevherlerini ematen birakan kimse, bunları oteldeki odasinda birakandan daha akıllıca hareket etmiştir. İkincinin hukukî durumu neden ilkininki gibi elverişli olmalıdır, gerçekten anlaşılamamaktadır. Bu gö̀ üşü ben senelerce önce müdafaa ettim. Hollanda Mukayeseli Hukuk Derneği 1968 Aralık ayında aynı anlamda düşüncesini ifade etti.

2. Kanaatımca çarşı ve pazarlara ilişkin özel hukukî düzenleme kaldırılmalıdır. Bedelin iadesi kuralının Ortağ Çağda çifte anlamı vardı: Hükümdarlar bu kural vasıtasıyla çarşı ve pazarlardaki ticareti teşvik edebiliyorlardı; Alıcıdan satm aldı̆̆ı eşya istihkak davası ilc gcri alıdığında, satıcının zapta karşı teminat sorumluluğu, bir hafta Marsilya'da d'ğer hafta Lion'da bulunan göçebe çarşı-pazar alıcıları için tamamen anlamsız olacağı için, pazard:ki alıcmın özel bir himayeye ihtiyacı vardı. Bugün çalınmış eşyalar (örmeğin bisikletler), pazarda, başka herhangi bir yerde olduğu gibi, çok daha tehlikesizce satılmaktadır. Paz rlara ilişkin ö el bir düzenlemeyi gerektirecek tek bir delil görmüyorum. Benim Italyan Hukukukunu benimsemek ve iyi inançlı alıııı her zaman himaye etmek şeklindeki önerim benimsenecek olursa, bu özel düzenlemeye artık gerek kalmaz.

3. Birçok hukuk sistemlerinin ivazlı ve ivazsız iktisapta bulunan müktesipler arasında yaptıkları farklı işlem bana doğru gelmektedir. Actio Pauliana'nn klâsik öncülerinin yanında Ulpianus'un D. 42,8,6,11 de ifade ettikleri bugün de geçerlidir. Ivazsız iktisapta bulunan iyi inançll müktesip, iktisap ettiği esyaya vermĕge mecbur bırakılsaydı, ona karşı haksız hareket edilmis olmazdr; "Cum lucrum ex torqueatur non damnum infligatur» ( kârdan mahrum kalmıldığı için, zarara uğ:anılmaz) Ưưüncü şahsa karşı rei vindicatio davası açıı bilsa, actin Pauliana halinde üçüncui şahsm iştirak ettiği işlemlerin iptal edilmesi ve kendisine doğan zararların tazmin ettirilmesi doğrudur. Kanaatımca ancak, malik olmayandan bir ivaz karşılı̆̆mda iktisapta bulunan ucçüncü şahıs, asıl malikin istihkak davasına karşı himaye edilmeye lâyıktır.

4. Bilhassa bu haller için (ve bulunmuş taşımır eşyalar için de) iki veya üç yıldan fazla sürmeyen kısa bir kazandırıcı zamanaşımı koymak bana uygun görünüyor. 
5. Şimdi konferansımın başında zikrettiğim emniyetin kötïye kullanılmasına konu olan köpek olayına dönüyorum. Asıl malik için büyük bir değer taşıyan böyle bir eşyanm emanet bırakılması halinde, bu eşyanın üçüncü şahısta kalmasına assl malikin katlanması hukukî hissimizle bağdaşmamaktadır. Úçüncü şahsa mamelekî bir zarar vermekten kaçınilırsa, onun çıkarına yeter derecede uygun davranılmış olur. Bu konuda Isveç'teki ömek hatırlanmalı ve eşyanm önceki malik için çok kıymetli olduğu hallerde, eşyayı üçüncü şahıstan iki veya üç yıllık belli bir süre içinde değiş-tokuş kıymetine uygun bir bedel karşılığında geri alma hakkunı önceki malike tanımalıdır. Ủçüncü şahıs malik olmusşa, hakim tarafından bu bedel karşılı̆̆ında eşyanın asıl malike teslimine zorlanılabilmelidir.

Böylece Hukuk Tarihine ve Mukayeseli Hukuka ilişkin araştırmamızın sonuçları, malik olmayandan edinilen taşınırın mülkiyetinin iktisabı konusunda hukukun ileriye götürülmesinde belki biraz yardımcı olabilir. 